\title{
The Chemical Percolation Devolatilization Model Applied to the Devolatilization of Coal in High Intensity Acoustic Fields
}

\author{
Carlos A. G. Veras ${ }^{a}$, João A. Carvalho Jr. ${ }^{* b}$ and Marco A. Ferreira ${ }^{c}$ \\ ${ }^{a}$ Departamento de Engenharia Mecânica, Universidade de Brasília, 70910-900, Brasília - DF, Brazil \\ ${ }^{b}$ Departamento de Energia, Universidade Estadual Paulista, Campus de Guaratinguetá, 12516-410, \\ Guaratinguetá - SP, Brazil \\ ${ }^{c}$ Laboratório Associado de Combustão e Propulsão, Instituto Nacional de Pesquisas Espaciais, 12630-000, \\ Cachoeira Paulista - SP, Brazil
}

\begin{abstract}
Neste trabalho, um modelo de percolação química (CPD), desenvolvido para o cálculo da evolução dos produtos de pirólise de partículas de carvão, foi estendido de forma a ser empregado em regimes de degradação térmica sobre a influência de campos acústicos de alta intensidade, típicos de combustores do tipo tubo de Rijke. As oscilações acústicas incrementam os processos de transferência de calor e massa no leito de combustível, bem como na região livre acima do mesmo. Os resultados obtidos em simulações com um combustor do tipo Rijke mostraram um aumento nas taxas de evaporação de água e de degradação térmica das partículas. O modelo de percolação química empregado, no regime pulsante, permitiu o cálculo da evolução dinâmica de $\mathrm{CO}, \mathrm{CO}_{2}, \mathrm{CH}_{4}, \mathrm{H}_{2} \mathrm{O}$, outros gases leves e alcatrão, importantes no processo de ignição e estabilização de chamas. $\mathrm{O}$ modelo também forneceu a quantidade e forma dos compostos nitrogenados liberados no processo de pirólise que são indispensáveis nas estratégias para abatimento da emissão de poluentes $\left(\mathrm{NO}_{\mathrm{x}}\right)$ em regimes de queima excitados por oscilações acústicas.
\end{abstract}

The chemical percolation devolatilization model (CPD) was extended for the prediction of drying and devolatilization of coal particles in high intensity acoustic fields found in Rijke tube reactors. The acoustic oscillations enhance the heat and mass transfer processes in the fuel bed as well as in the freeboard, above the grate. The results from simulations in a Rijke tube combustor have shown an increase in the rate of water evaporation and thermal degradation of the particles. The devolatilization model, based on chemical percolation, applied in pulsating regime allowed the dynamic prediction on the yields of $\mathrm{CO}, \mathrm{CO}_{2}, \mathrm{CH}_{4}, \mathrm{H}_{2} \mathrm{O}$, other light gases as well as tar which are important on ignition and stabilization of flames. The model predicted the quantity and form of nitrogen containing species generated during devolatilization, for which knowledge is strategically indispensable for reducing pollutant emissions $\left(\mathrm{NO}_{\mathrm{x}}\right)$ in flames under acoustic excitation .

Keywords: chemical percolation devolatilization model, acoustic fields, Rijke tube

\section{Introduction}

With the decline of oil reserves expected for the first half of this century, coal raises as a potential candidate for energy production in large scales. Environmental concerns with the more stringent regulations on emissions is increasing the coal research for a more profound understanding on the possible harmful pollutants originated during its utilization. At present, coal is burned

*e-mail: joao@feg.unesp.br mostly in pulverized systems and in fluidized beds for gasification. Devolatilization of coal through heating is an important process in ignition, stabilization and emissions of the flames in combustion, and in the composition of the remaining char in gasification. The chemical structure of coal can be used to predict pyrolysis products from the thermal degradation, which includes, mostly, light gases, tar and char. Figure 1 depicts the schematic representation of a hypothetical coal molecule (Pittsburgh Seam bituminous), adapted from Solomon et al., ${ }^{1}$ along with a simplified representation of the main pyrolysis stages. 


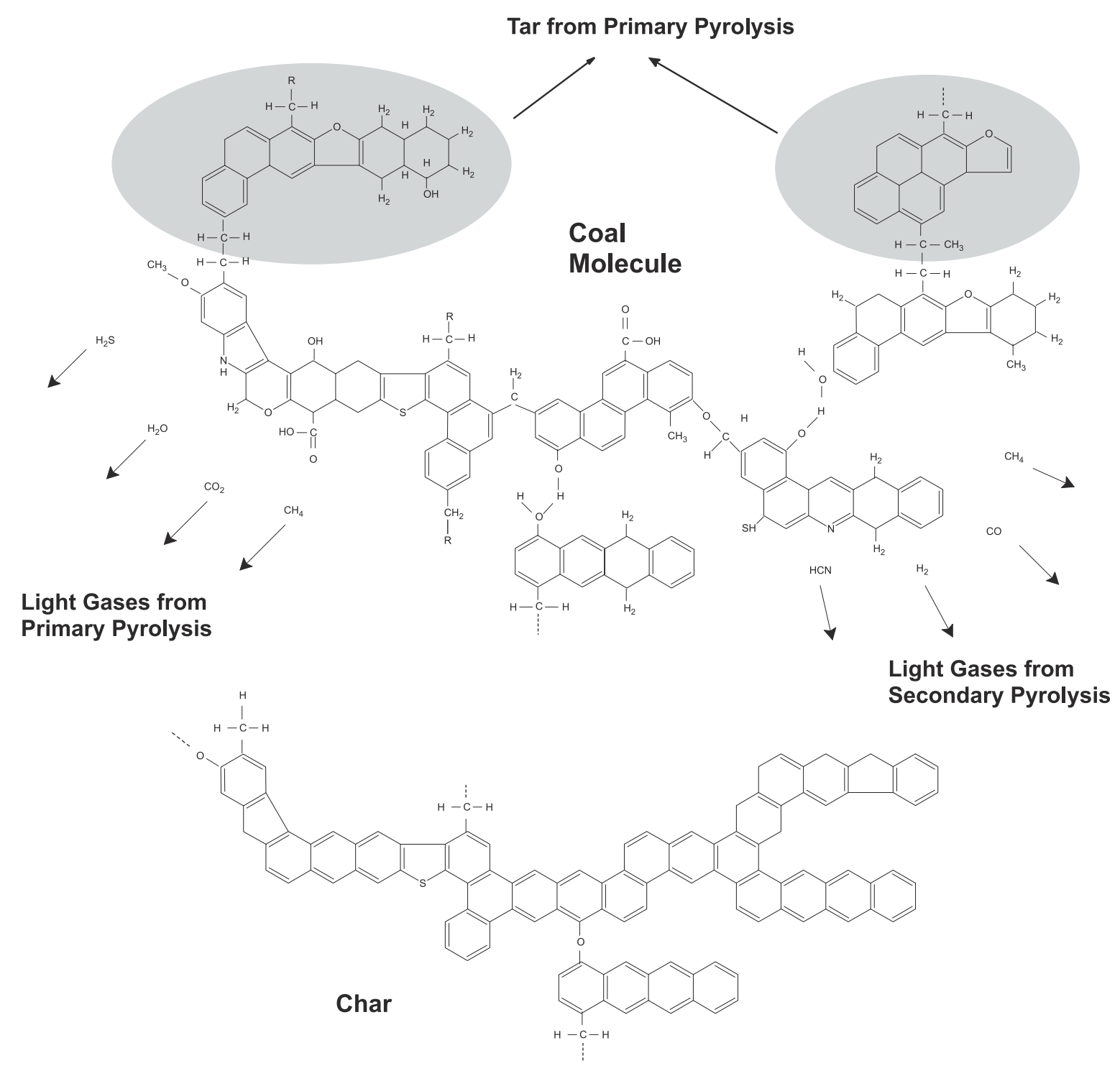

Figure 1. Coal molecular structure and devolatilization (adapted from Solomon et al. ${ }^{1}$ )

This structure shows the chemical and functional group compositions consisting of aromatic and hydroaromatic clusters linked by aliphatic bridges whose devolatilization process can be described dynamically in nine steps. ${ }^{2}$ In general, the whole process can be thought as having two important stages, primary and secondary pyrolysis: the decomposition of individual functional groups in the coal to produce light species and the decomposition of the macromolecular network, which produces smaller fragments evolving as tar. $^{2}$

Due to environmental concerns ( $\mathrm{NO}_{\mathrm{x}}$ emissions), predictions for nitrogen containing species in coal devolatilization is of major importance and, therefore, some attempts have been made recently to enhance the applicability of the devolatilization models based on chemical structure where release of nitrogen compounds is taken into account.

In this work, the latest version of the chemical percolation devolatilization model ${ }^{3}$ (CPDNLG) is used to calculate the drying and devolatilization of solid fuel particles (coal) under acoustic fields. The code name, NLG stands for nitrogen and light gases whose release rates are predicted by this model's version. The model thus calculates the release rate of nitrogen, tar and light gases $\left(\mathrm{CO}, \mathrm{CO}_{2}, \mathrm{CH}_{4}\right.$, and $\left.\mathrm{H}_{2} \mathrm{O}\right)$ from coal pyrolysis. More detailed information is given in the "Coal Devolatilization and the CPD Model" section as well as a dynamic description of the pyrolysis process as depicted in Figure 1.

In a practical point of view, this work studies the applicability of the model in advanced combustion 
systems such as pulsating flow in Rijke tubes. Some relevant aspects of pulsating combustion are provided in the following.

Acoustic oscillations are observed in several practical combustion processes. When under control these pressure oscillations, which are in general coupled to oscillatory heat transfer, result in the so called pulse combustion process. The benefits of pulse combustion include increased mixing between oxidizer and fuel, high convective heat transfer rates, efficient combustion, fuel economy, and, in certain cases, reduced pollutants emission. $^{4,5}$

Heat generated oscillations were discovered in 1777 by Higgins, with hydrogen singing flames in tubes. ${ }^{6}$ Later, in 1859, Rijke observed that oscillations were excited when a previously heated metallic gauze was placed in the lower half of a vertical open-ended tube. ${ }^{7}$

The condition for amplification of any pressure perturbation in a flow is established by the Rayleigh criterion. ${ }^{7}$ The criterion states that if the heating rate transferred periodically to the flow is in phase with the pressure perturbation, the pressure amplitude will increase up to a limiting value. This value is given by a heat balance between the energy gained by the oscillation and that dissipated by the system. Oran and Gardner ${ }^{8}$ attribute to $\mathrm{Chu}^{9}$ a physically consistent foundation for the mathematical formulation of Rayleigh criterion. Ferreira and Carvalho ${ }^{10}$ developed a simple derivation of the criterion in the integral form. Using the criterion mathematical formulation, Carvalho et al. ${ }^{11}$ proved, with experimental confirmation, that maximum amplitude acoustic oscillations of the fundamental mode were obtained when the heating process occurred in a Rijke tube at $\mathrm{L} / 4$, where $\mathrm{L}$ is the length of the tube.

A Rijke pulse combustor is obtained when the heat generated by the original metallic gauze is produced by a combustion process. This type of combustor is a very simple device, since it has no moving parts. Experiments with Rijke combustors have been reported for different types of fuels, including wood chips, ${ }^{12}$ unpulverized coal, ${ }^{13,14}$ charcoal, ${ }^{15}$ agriculture residue, ${ }^{16}$ ethyl alcohol, ${ }^{17,18}$ and propane. $^{19}$

When a solid unpulverized fuel is burned in a Rijke combustor, most of the drying, devolatization and both homogeneous and heterogeneous combustion occur in the combustion bed. As the particle becomes lighter, it is carried by the gas flow and continues burning heterogeneously in the freeboard region. The cited processes occur all above the bed for originally small particles, as they are immediately carried by the gas flow. Figure 2 presents a scheme of the solid fuel combustion in a Rijke combustor.

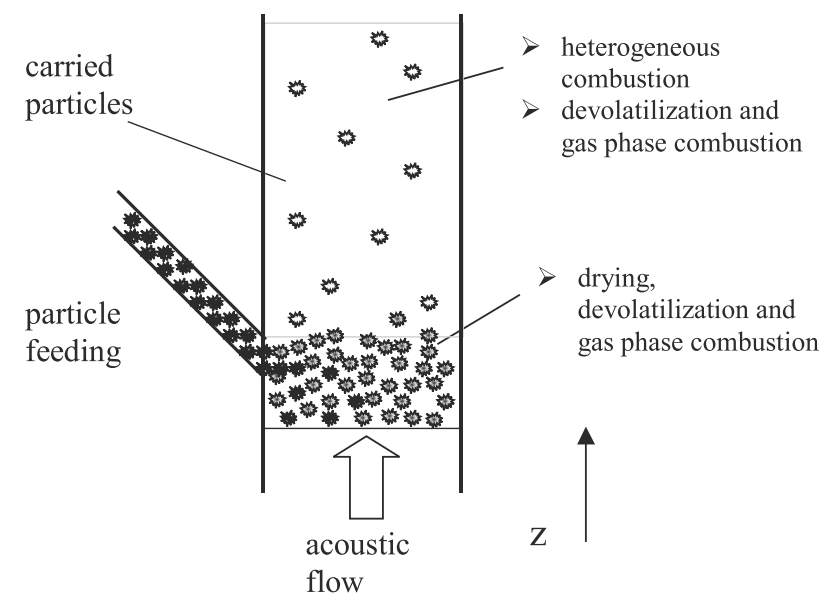

Figure 2. Scheme of the solid fuel combustion process in a Rijke tube

In this paper the chemical percolation devolatilization model (CPD model) is applied to investigate the devolatilization of coal and the related effects of pulsating flow as a rate controlling process on the thermal degradation of the solid fuel particles. We also employed the model to predict dynamically the evolution of light species, tar and nitrogen containing species which are important parameters for flame stabilization ${ }^{20,21}$ and control strategies for $\mathrm{NO}_{\mathrm{x}}$ emissions. ${ }^{22}$

\section{Coal Pyrolysis and the CPD Model}

Different models have been presented for coal devolatilization. The mass released from pyrolysis may be calculated by models that use simple, double or even multiple rate equations. The difficulties arise from the physical and chemical processes that occur as thermal degradation proceeds. A set of parallel reactions is observed along with physical changes in the particle shape and structure. The models based on double rate equations have been used extensively but agreement is better at high temperature devolatilization and heating rates. ${ }^{23}$

In coal thermal degradation, Anthony and Howard ${ }^{24}$ have observed that water (not from evaporation) is released first, accompanied by carbon dioxide, carbon monoxide, higher hydrocarbons (including tar), ethane, methane, and finally hydrogen with substantial overlapping in the rate of production. Experimentally, Suuberg et al. ${ }^{25}$ observed that $\mathrm{CO}, \mathrm{CO}_{2}$ and $\mathrm{H}_{2} \mathrm{O}$ dominate the lignite volatiles, while the main products from bituminous coals are tar and light hydrocarbons. Unger and Suuberg ${ }^{26}$ developed a model to explain the devolatilization behavior of softening coals. For softening coals, water and $\mathrm{CO}_{2}$ are released first, preceding metaplast formation. This metaplast is the source of tar and gases, including hydrogen. 
The pyrolysis process is governed not only by chemistry having also heat and mass transfer playing decisive roles. As pointed out by Solomon et al. ${ }^{2}$ the chemistry of pyrolysis includes the decomposition of individual functional groups in the coal producing species that are mainly light gases. In parallel the decomposition of the macromolecular network is observed to produce smaller fragments, which evolve as tar. They also pointed out that the network decomposition is a complicated mixture of bridge breaking, cross linking, hydrogen transfer, substitution reactions, concerted reactions and so on. The mass transfer that conveys pyrolysis products to the exterior of the particle includes diffusion in the decomposing solid or liquid, vaporization of the light network fragments, gas phase diffusion and pressure-driven convective transport which may occur within pores, by bubble movement or a combination of these. ${ }^{2}$

A chemical description of pyrolysis may be, approximately, abridged in the following steps: ${ }^{2}$ (i) disruption of hydrogen bonds; (ii) vaporization and transport of non-covalent bonded "guest" molecules; (iii) low temperature cross-linking (for low rank coals); (iv) bridge breaking to fragment the macromolecular network; (v) hydrogen utilization to stabilize free radicals; (vi) vaporization and gas phase transport of light fragments; (vii) moderate temperature cross-linking to re-solidify the macromolecular network; (viii) decomposition of functional groups to produce light species; and (ix) high temperature condensation of the macromolecular network by hydrogen elimination. Some of these steps are represented in Figure 1. The "marked" areas depict structures that are high molecular weight hydrocarbon evolving as tar from the primary pyrolysis of coal. Light gases are also liberated in this stage. Secondary pyrolysis occurs by char condensation and crosslinking, also releasing a great deal of light species. These concepts, of course, are not all representative of the complicated chemistry that occurs. However, most of them, to different extent, must be incorporated in phenomenological models.

Recently, the improved knowledge of the coal polymeric structure allowed the development of more reliable devolatilization models, which are based on disintegration of its macromolecular structure, as described earlier. There are three phenomenological models that predict thermal degradation of coal from its organic structure. The FLASHCHAIN $^{27}$ and the CPD model are similar in the number of input parameters while the FG-DVC ${ }^{28}$ model is based on a much larger set of data inputs. These input data are, among others, kinetic parameters, coal polymeric structure and elemental composition. In spite of the number of input data used in each of these models, they all have some features that are common: ${ }^{3}$ (i) the coal is described with structural parameters obtained experimentally; (ii) tar release and bridge scission are described by means of statistical network model; (iii) first order reaction rates with distributed activation energies are used for depolymerization, crosslinking and light gas formation; and (iv) a correlation of vapor pressure with tar molecular weight to model the evaporation of tar. The great advantage of such models relies on their phenomenological nature compared to the empirical approach observed in former ones.

Among the models, the FLASHCHAIN was developed to predict yields and products characteristics for any coal for any operating conditions..$^{29}$ The FLASHCHAIN model can be applied in situations where ultimate analysis is the only information available. In the model, there are four generic structural components that are used to characterize coal: aromatic nuclei, labile bridges, char links and peripheral groups. Labile bridges are the key reaction centers in FLASHCHAIN since their conversion governs the evolution rates and yields of both gas and tar. ${ }^{30}$

In the FG-DVC model the thermal evolution of the coal matrix is modeled with a network model. This network consists of nodes, representing polymer clusters, and the connection between them. The FG model simulates the thermal evolution of various functional groups. The DVC model is responsible for predicting the depolymerization, vaporization and crosslinking processes that occur in the coal polymer network. Thermal evolution in FG model is calculated with parallel first order reactions along with a distributed activation energy formulation. ${ }^{2}$

The CPD model has the capability of predicting the distribution of light gases during devolatilization into $\mathrm{CO}$, $\mathrm{CO}_{2}, \mathrm{CH}_{4}, \mathrm{H}_{2} \mathrm{O}$ and other light hydrocarbons. It also predicts the quantity and form of nitrogen released during coal devolatilization. ${ }^{3}$ The model has a general applicability that allows predictions for American and non-American coals. The network decomposition in the model is grounded on five procedures: (i) a description of the parent coal based on quantitative nuclear magnetic resonance spectroscopy measurements of chemical structure; (ii) a bridge relation mechanism with associated kinetics; (iii) percolation lattice statistics to determine the relationship between bridge breaking and detached fragments which are tar precursors; (iv) a vapor-liquid equilibrium mechanism to determine the fraction of liquids that vaporize; and (v) a cross-linking mechanism for high molecular weight tar precursors to reattach to the char. ${ }^{31}$

\section{Modeling}

Besides devolatilization, the CPD model is also able to calculate drying. Moisture evaporation rate for lignite 
and high-moisture coals are modeled based on the evaporation of a spherical drop of water. The mass transfer coefficient is obtained from a correlation with the Sherwood number. The CPDNLG model ${ }^{3}$ had to be modified to take into account the acoustically oscillating flow. Nusselt and Sherwood numbers were corrected with a parametric equation proposed by Yavuzkurt et al. ${ }^{32}$

Since the CPDNLG model considered the particle as isothermal it is relevant to discuss the effects of heat and mass transfer in coal pyrolysis in order to limit the applicability of the model. In the CPDNLG model the convection of tar and light gases is assumed to be rapid compared with the chemical reactions related to the pyrolysis. Therefore, the model should be applied for cases where mass transfer in not a limiting process.

Several studies have been conducted regarding the effects of mass transfer in coal pyrolysis (James and Mills, ${ }^{33}$ Simons, ${ }^{34}$ Phuoc and Durbetaki, ${ }^{35}$ and Fu et al. ${ }^{36}$ ). Simons ${ }^{34}$ studied the coupling between volatiles transport within the coal pore structure with the kinetics of devolatilization. The model, however, was isothermal and some other assumptions restricted its applicability to particles larger than $1.0 \mathrm{~mm}$. They pointed that secondary pyrolysis may be significant for bituminous coal, due to the delay on volatiles fluid transport, thus suggesting that devolatilization rate is strongly dependent on particle size. Phuoc and Durbetaki ${ }^{35}$ combined heat and mass transfer with kinetics to analyze coal particles undergoing pyrolysis. To take into account the deposition reactions they assumed volatiles to be reactive and non-reactive. In their formulation, the transport of volatiles through the pores was controlled either by diffusion or convection depending on pore size. They suggested that pyrolysis rate is subjected to heat transfer control. The particle size influences only the time required to complete the devolatilization. In fact, for larger particles the outer region is more permeable since porosity is higher due to earlier pyrolysis. Therefore, the resistance to mass transfer is decreased.

Next, we investigate in more detail the effects of particle internal gradients in coal pyrolysis.

Since devolatilization is a dynamic process the analysis should be based on characteristic times for internal and external gas phase heat transfer accompanied by a kinetic rate for pyrolysis. Among many simplified criteria summarized in the review of Solomon et al., ${ }^{2}$ those which are considered more reliable are based on internal temperature gradient and the difference in kinetic rates between the surface and the center of the particle. This criterion, however, overestimates the effects of the temperature gradient because a large portion of the mass is close to the surface. It is also quite stringent because, originally, it was established for predicting kinetic rates in coal experiments. In practical applications it is more relevant to verify the effects of particle size in the rate production of volatiles and total weight loss. Based on this, the difference in pyrolysis rate and temperature between the surface of the particle $\left(R_{s}\right)$ and the center $\left(R_{c}\right)$ was substituted by the difference between the surface and a radius $\left(\mathrm{R}_{90}\right)$ for which $90 \%$ of particle's mass is located. The ratio $\mathrm{k}_{\mathrm{s}} / \mathrm{k}_{90}$ was then calculated for $\mathrm{R}_{90}$ and $\mathrm{R}_{\mathrm{s}}$ along with the difference in solid temperature for these two locations. Considering that phenomenological models calculate the rate of pyrolysis from a large number of time dependent parameters, this analysis turns to be more complicated. Therefore, the CPD model was implemented in the CMVC model ${ }^{23}$ (Continuous Model for Volatiles Combustion) for which one of the main features is to treat particles as nonisothermal. In the CMVC model, the thermophysical properties such as specific heat and thermal conductivity are a function of temperature and degree of conversion (pyrolysis). More details about the CMVC model can be seen elsewhere. ${ }^{20-23}$

With the help of the CMVC model we investigated some of the criteria for limiting particle size in the CPDNLG model. For the predictions, the particle was divided in 21 control volumes. Figure 3 shows the temperature difference $\left(\mathrm{T}_{\mathrm{s}}-\mathrm{T}_{90}\right)$, overall conversion $\left(\mathrm{M} / \mathrm{M}_{\mathrm{o}}\right)$ and the pyrolysis ratio $\left(\mathrm{k}_{\mathrm{s}} / \mathrm{k}_{90}\right)$ for some selected degree of solid thermal degradation for a $2.0 \mathrm{~mm}$ particle diameter. Gas temperature was set to $1300 \mathrm{~K}$. Predictions were from the CMVC model; therefore, temperature distribution is calculated inside the particle as well as local conversion. Since the onset for pyrolysis is time dependent, at $1 \%$ conversion the temperature at the surface is $778 \mathrm{~K}$ while at $\mathrm{R}_{90}$ it is $584 \mathrm{~K}$. Therefore, it is expected that evaporation has already taken place, and overlapping of drying and pyrolysis, if occurred, was negligible. At 10\% conversion the temperature difference is about $183 \mathrm{~K}$ and the ratio of pyrolysis $\mathrm{k}_{\mathrm{s}} / \mathrm{k}_{90}$ is significant (Figure 3) for this quite stringent criterion. However, at $15 \%$ conversion the ratio falls rapidly to 0.7 meaning that non-isothermality is now of little importance. As pyrolysis continues, both the temperature difference and the $\mathrm{k}_{\mathrm{s}} / \mathrm{k}_{90}$ ratio decrease sharply up to $51 \%$ total conversion. During the time that pyrolysis takes place, blowing effects (Stefan flow) prevents oxygen to reach the particle surface thus eliminating char oxidation. Also, this blowing effect reduces the convective heat transfer to the surface of the particle thus reducing the Biot number, implying that the applicability of the lumped capacitance method is extended. This criterion, however, is commonly applied to derive kinetic rates of pyrolysis from experiments, as mentioned before. 


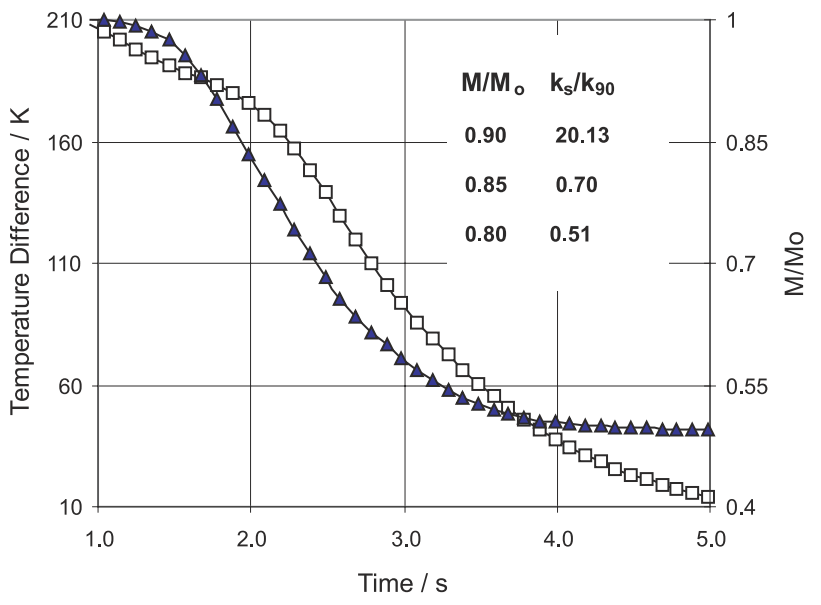

Figure 3. Pyrolysis conversion ( $\mathbf{\Delta})$ and temperature difference ( $\square$ )as function of time

Since we are primarily concerned with the rate of volatiles production and ultimate weight loss, we have conducted simulations with both models to compare yields against time for a $2.5 \mathrm{~mm}$ particle and the ambient gas temperature set at $1600 \mathrm{~K}$. Particle weight loss against time is shown in Figure 4 as calculated by the CMVC and CPDNLG models. The difference in the mean weight loss up to $2.0 \mathrm{~s}$ pyrolysis time is not so significant. However, the total weight loss is $60 \%$ in the CPDNLG model, against $52 \%$ in CMVC model. This difference in the overall production can be explained by the particle temperature gradient. In the non-isothermal model (CMVC) the heating rate of the particle interior is retarded and pyrolysis takes place at lower mean temperature. We also verified any possible overlapping for chemical and physical processes. The predictions have shown that drying and pyrolysis occur simultaneously in the first $20 \%$ of the conversion and, therefore, may significantly alter the composition of the volatiles. Then, the CPDNLG model should be employed with care for this particle size and temperature

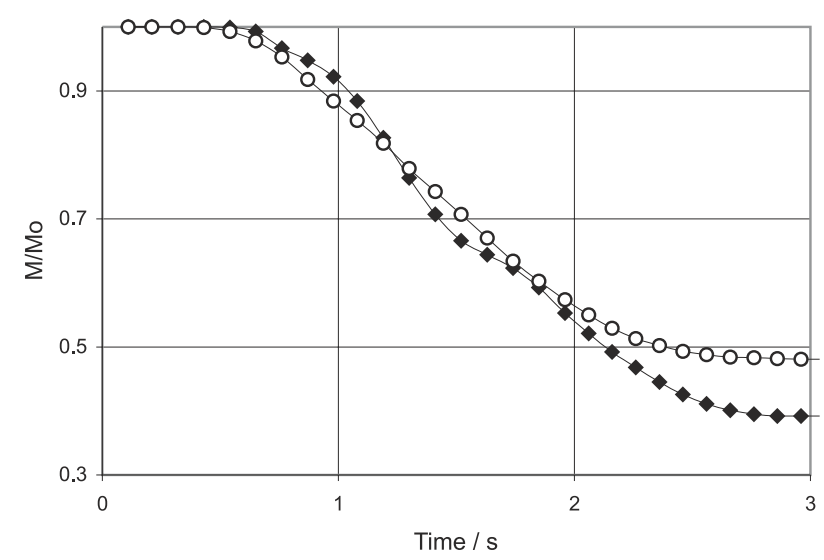

Figure 4. Pyrolysis conversion from CMVC (O) and CPDNLG ( $\bullet$ models for ambient gas temperature set to $1600 \mathrm{~K}$ and $d=2.5 \mathrm{~mm}$ level. Hence, in this work, we limited our calculations for particles smaller than $2.5 \mathrm{~mm}$ diameter.

The fuel is fed to the acoustically vibrating bed (Figure 2) with some moisture, at ambient temperature. In the bed, particle heating followed by drying and devolatilization take place. Since this region is rich in oxygen, burning is assumed to occur solely in the gas phase. Blowing effects prevent oxygen to reach the surface of the particle; therefore, heterogeneous oxidation is not observed. The combustible gases are those from the thermal degradation of the particles (tar and light gases). Therefore, the particles retain their volume but density decreases sharply. At some point, the combination of particle size and density may favor dragging and the burning would take place in the freeboard of the combustor. When devolatilization is near completion, particles are highly porous, blowing vanishes, and heterogeneous combustion would then be favored. Prediction of where the particle is located during devolatilization is, therefore, important. To do so, the particle motion is calculated. In pulsating combustion, Re is usually less that 1000 ; thus, the drag coefficient may be calculated by: $: 37$

$\mathrm{C}_{\mathrm{d}}=\frac{24}{\operatorname{Re}}\left(1+0.15 \operatorname{Re}^{0.687}\right)$,

where Re is the Reynolds number based on particle diameter.

First the dynamic behavior of two particles sizes with the same initial density are predicted. Gas velocity is calculated by

$v_{g}=v_{a v}+v_{a m p} \sin (2 \pi f t)$,

where $v_{a v}$ is the gas average velocity, $v_{a m p}$ is the amplitude of the fluctuating gas velocity, $f$ is the frequency of oscillation, and $t$ is the time. Following values reported by Carvalho et al. ${ }^{11}$ we will take $v_{a v}=2 \mathrm{~m} . \mathrm{s}^{-1}, v_{a m p}=10 \mathrm{~m} . \mathrm{s}^{-1}$, and $f=70 \mathrm{~Hz}$. Gas properties are calculated assuming an average temperature for the reactor as $1300 \mathrm{~K}$. Density of particles is $1270 \mathrm{~kg} / \mathrm{m}^{3}$. An example calculation is presented in Figure 5 for a particle whose diameter $d$ is $2.0 \mathrm{~mm}$ and in Figure 6 for a smaller particle $(d=0.5 \mathrm{~mm})$. In Figure 5, particle displacement and gas and particle velocities as function of time are presented for the acoustic flow. Despite the great variation on gas velocity the particle is heavy enough to stay stationary on the grate, where drying and devolatilization take place.

\section{Results and Discussion}

Drying and devolatilization of a coal (Illinois number 6), $2.0 \mathrm{~mm}$ diameter, was investigated for gas velocity 


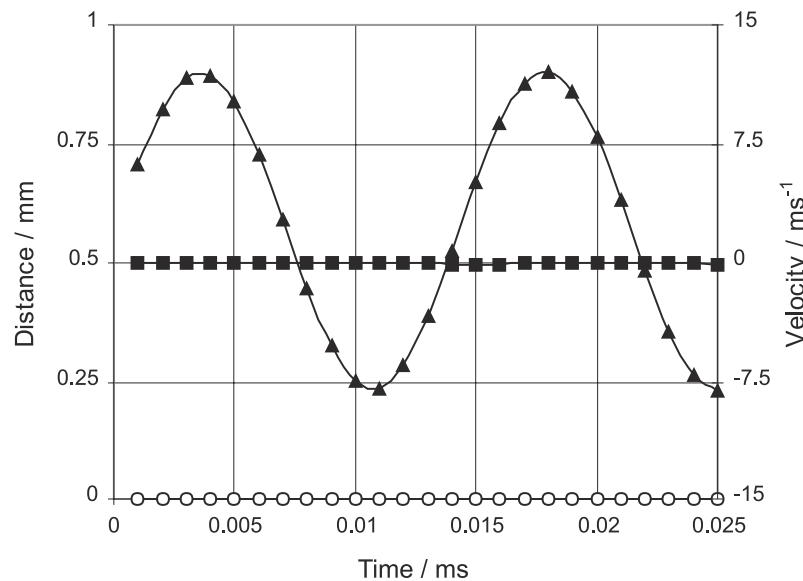

Figure 5. Particle displacement $(\mathrm{O})$, gas $(\mathbf{A})$ and particle (ם) velocities as function of time; $d=2.0 \mathrm{~mm}$

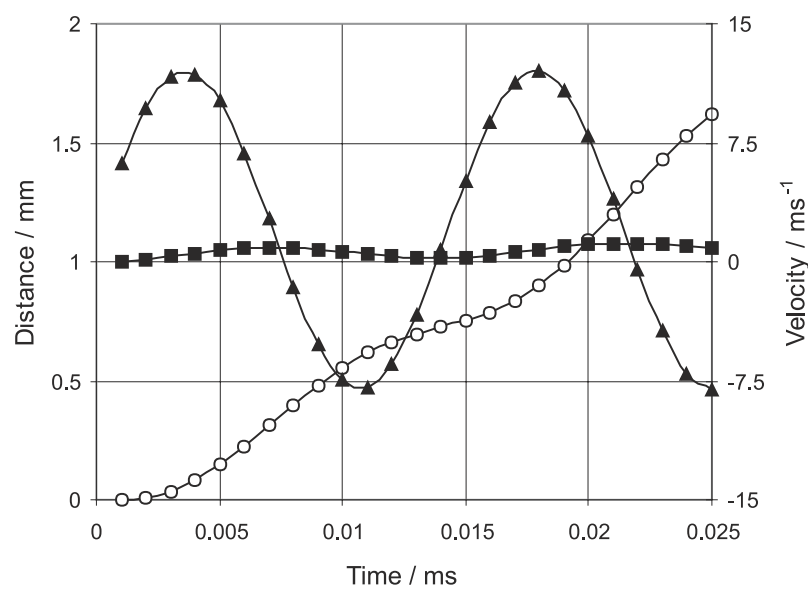

Figure 6. Particle displacement $(\mathrm{O})$, gas $(\boldsymbol{\Delta})$ and particle $(\mathbf{\square})$ velocities as function of time; $d=0.5 \mathrm{~mm}$

assumed to vary according to equation 2 for oscillating and non-oscillating flows. The latter was achieved by simply setting $v_{a m p}=0 \mathrm{~m} \cdot \mathrm{s}^{-1}$. The coal elemental composition is $74.12 \% \mathrm{C}(\mathrm{DAF}), 4.96 \% \mathrm{H}, 1.45 \% \mathrm{~N}$, $13.18 \% \mathrm{O}$, and $6.29 \% \mathrm{~S}$. The mass fraction of moisture and ash in the parent coal are 0.0328 and 0.1130 , respectively. Gas temperature was fixed at $1330 \mathrm{~K}$. Prediction for higher temperature $(1600 \mathrm{~K})$ was also carried out.

Figure 7 shows the particle temperature, tar and light gases yields as a function of time for the case where the oscillations occur. Figure 8 shows the same case of Figure 7 , but considering non-oscillating flow.

Comparing both figures it is clear that the same levels of volatiles production (tar and light gases) and temperature are obtained for both oscillating and nonoscillating flows. However, in the oscillating flow, particle heating rate and drying are much faster, since devola-

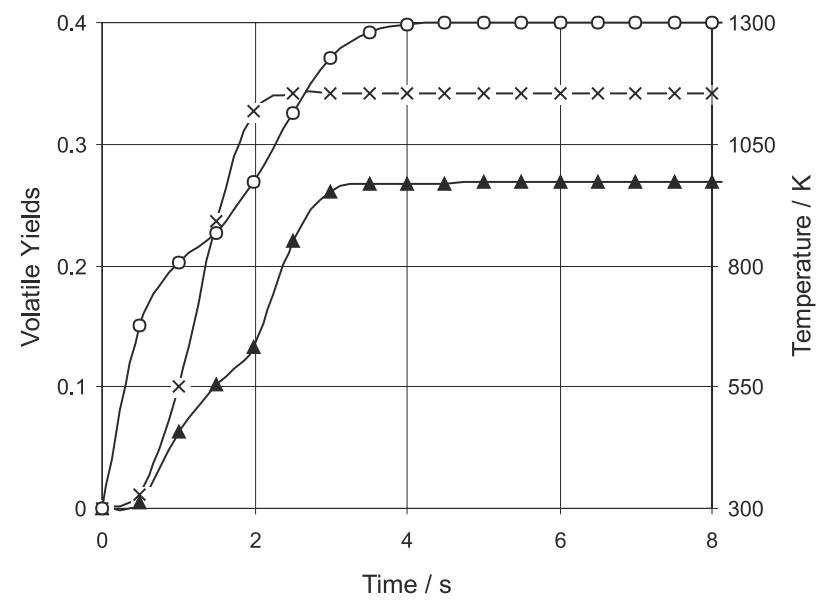

Figure 7. Devolatilization and heating of a particle in an oscillating flow ( $\bigcirc$ - gas, $\times$ - tar, $\mathbf{\Delta}$ - temperature)

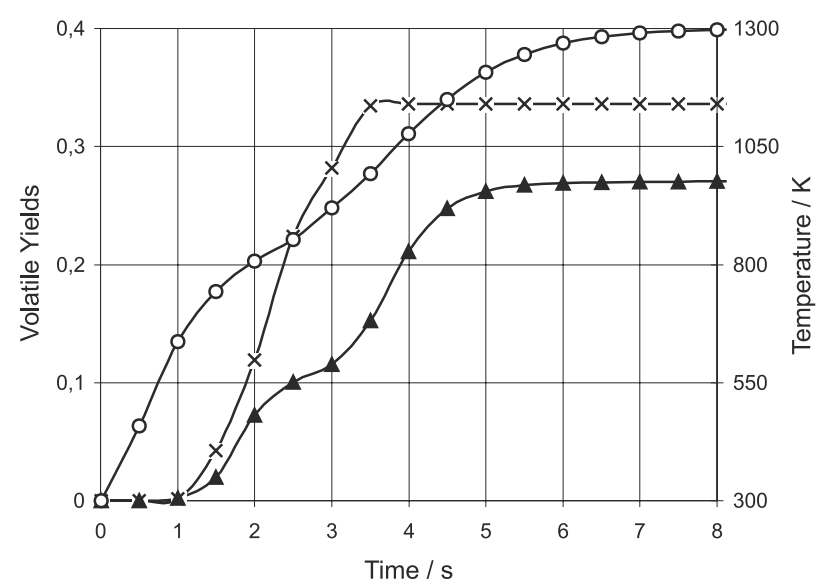

Figure 8. Devolatilization and heating of a particle in a non oscillating flow ( $\bigcirc$ - gas, $\times$ - tar, $\boldsymbol{\Delta}$ - temperature)

tilization rates are higher. Total tar (34.2\%) and light gases $(26.8 \%)$ yields were reached in less than 2.5 and $4.0 \mathrm{~s}$, respectively. In the non-oscillating flow, almost similar yields were reached only after $4.0 \mathrm{~s}$ for $\operatorname{tar}(33.6 \%)$ and $6.5 \mathrm{~s}$ for light gases (27\%). The drying of the particle, not shown in the figures, is faster by virtue of the higher mass transfer in the boundary layer of the particle. In the oscillating flow the particle is dried after $0.15 \mathrm{~s}$ while in the nonoscillating flow the time necessary to completely dry the particle was twice longer, about $0.30 \mathrm{~s}$.

Summation of tar and volatiles yields gives $60.6 \%$ of combustible gases to be released and burnt in the gas phase. In Rijke tube combustors there is an optimum location for the heat source, which gives the highest intense acoustic field. As observed by Carvalho et al., ${ }^{11}$ the maximum amplitude of acoustic oscillations of the fundamental mode in a Rijke tube were obtained for heat addition at L/4. As 
consequence, the particles must be kept in the grate $(\mathrm{L} / 4)$ as long as they are releasing volatiles. For the conditions shown in Figure 6, the particle is located $10 \mathrm{~mm}$ above the grate at $2.84 \mathrm{~s}$, which correspond to $59.1 \%$ in the release of volatiles ( $\operatorname{tar}+$ light gases). Heterogeneous combustion, therefore, would take place in the freeboard. If particle temperature is high enough, char oxidation would take place mostly at the surface of the particle with little oxygen penetration (shrinking core model) with particle density remaining constant. The residence time in the freeboard region would be short and some means should be provided to collect and introduce the particles back to the grate. The particle size used in this prediction $(d=2.0 \mathrm{~mm})$ should be increased if heterogeneous combustion is also intended to occur in the bed. The type of coal also influences the motion of the particle because density varies for different coals. A more intense study should be carried out in order to obtain the ideal particle size for a specific objective.

The composition of light gases for the case in which oscillations are present is shown in Figure 9.

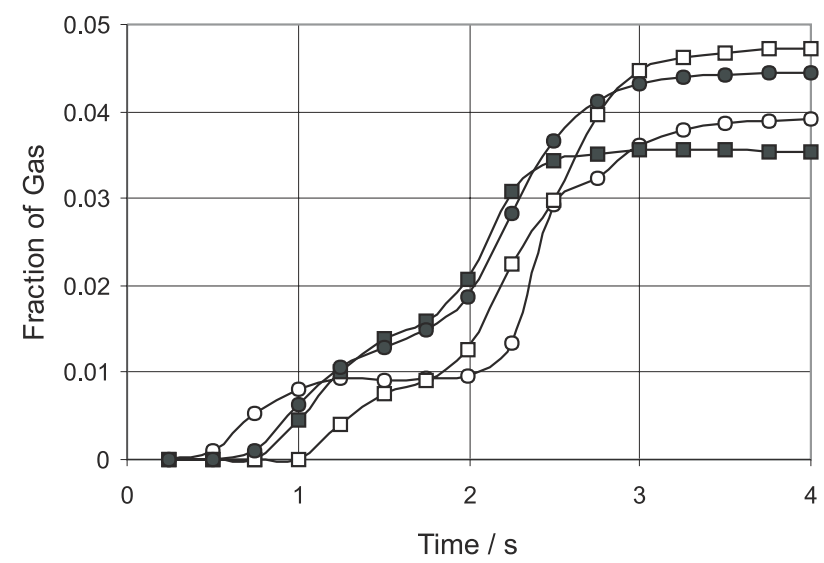

Figure 9. Fraction of devolatilization products $\left(\square-\mathrm{CO}, \mathbf{\square}-\mathrm{CH}_{4}, \mathrm{O}\right.$ - $\mathrm{CO}_{2}, 0$ - "other")

Figure 7 shows the amount of gas and char released as devolatilization progresses under the influence of acoustic excitation. Figure 9 indicates the major constituents of the gases. As it can be seen, up to $1.0 \mathrm{~s}$ devolatilization time, the rate of released of $\mathrm{CO}_{2}$ dominates followed by other gases (calculated by difference) and methane. $\mathrm{CO}$ has the lowest rate of production util $1.0 \mathrm{~s}$. From 1.5 to 2.0, methane yields dominate decaying rapidly to stabilize at about $2.5 \mathrm{~s}$. In this period the production of $\mathrm{CO}$ experiences an increase to be the major species after $3.0 \mathrm{~s}$. Combustible gases (excluding $\mathrm{CO}$ and $\mathrm{CH}_{4}$ ) collectively named "other" are produced at a rate which is comparable to that of $\mathrm{CH}_{4}$, until $2.3 \mathrm{~s}$, and similar to that of $\mathrm{CO}$ from this time to $4.0 \mathrm{~s}$. This dynamic process is very important in predicting ignition and flame stabilization in coal combustion. Since
$\mathrm{CO}_{2}$ yields dominate the first second of devolatilization, other gases and tar would appear as the major combustible species. Tar and methane dominates from some intermediate period and $\mathrm{CO}$ with tar are predominant species when devolatilization is near completion.

The CPD model can also track, dynamically, the nitrogen containing species release rates as devolatilization progresses. Figure 10 shows the fraction and form of nitrogen in the presence of an acoustic field.

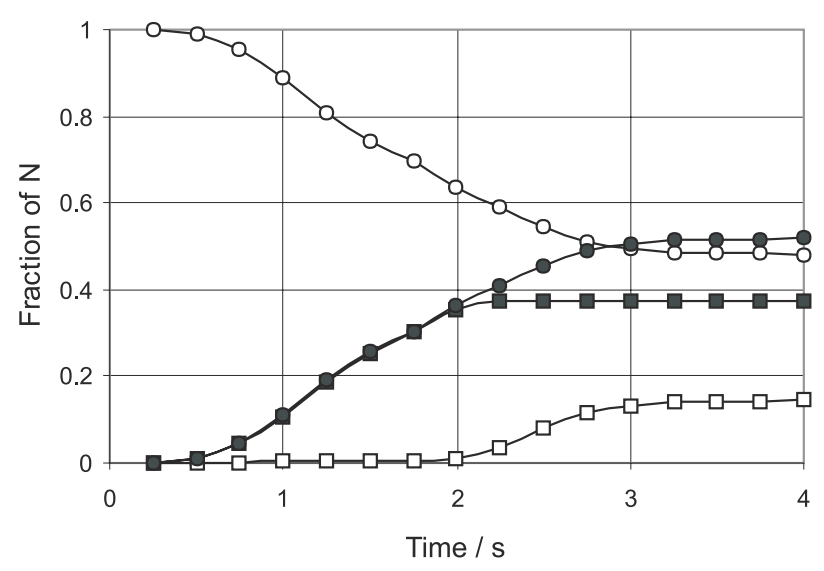

Figure 10. Fraction of nitrogen release as gas and remaining in char ( $\square$ - HCN, $\mathbf{\square}$ - tar, O - char, $\bullet$ - FTN)

The curves show that most of the nitrogen in coal is released in tar and very little $(\sim 17 \%)$ is released as $\mathrm{HCN}$. By the end of the devolatilization process, half of the original nitrogen in coal stay in the char while the other half escaped as HCN and in the tar, mostly in the latter. In both cases the results may indicate better strategies towards less emissions in coal flames under oscillatory conditions. One prediction was also carried out for the same conditions presented in Figure 7 but without acoustic fields. When volatiles release rate increased due to oscillations, nitrogen content in tar as $\mathrm{HCN}$ increased by $2.5 \%$ as well. Therefore, less nitrogen stays in char if devolatilization takes place in non-oscillatory flows but more nitrogen is released as light gas and tar.

The influence of particle size on drying and devolatilization was also verified for larger particles. Table 1 shows the predictions of total yields with the respective devolatilization times for different particle size in oscillating (OSC) and non oscillating (NOSC) flows.. The flow conditions are those for equation 2. In Table 1, it is shown the respective times for the asymptotic yields for total tar and total light gases for different particle sizes. Also, it is given the particle location at completion of pyrolysis which time is that for total light gases yields. By such means it is possible to locate the particle by the end of the devolatilization process. 
Table 1. Particle location, total tar and gas yields as function of time for oscillating and non oscillating flow

\begin{tabular}{|c|c|c|c|c|c|c|c|c|}
\hline & \multicolumn{2}{|c|}{$0.1 \mathrm{~mm}$} & \multicolumn{2}{|c|}{$0.5 \mathrm{~mm}$} & \multicolumn{2}{|c|}{$1.0 \mathrm{~mm}$} & \multicolumn{2}{|c|}{$2.0 \mathrm{~mm}$} \\
\hline & OSC & NOSC & OSC & NOSC & OSC & NOSC & OSC & NOSC \\
\hline$\% \operatorname{tar}$ & 40.0 & 39.2 & 37.2 & 36.1 & 35.5 & 34.7 & 33.8 & 33.4 \\
\hline time $(\mathrm{s})$ & 0.03 & 0.05 & 0.27 & 0.6 & 0.78 & 1.5 & 2.3 & 3.8 \\
\hline$\%$ gas & 24.3 & 24.6 & 25.4 & 25.8 & 26.3 & 26.5 & 26.7 & 26.7 \\
\hline time $(s)$ & 0.16 & 0.2 & 0.54 & 1.1 & 1.63 & 2.67 & 3.3 & 4.9 \\
\hline Location $(\mathrm{mm})$ & 31.8 & 38.5 & 87.4 & 135 & 183 & 74 & 27.0 & 0.0 \\
\hline
\end{tabular}

From Table 1, the decrease in tar production is clear as particle size increases. Gas yields are higher for larger particles at the expense of lower tar. These effects are associated to the time required for particle heating. For large particles devolatilization takes place at lower mean temperatures. Part of the tar that stayed in coal is converted to char, and part is released as light gases through secondary pyrolysis. The amount of char remaining in the original structure is higher for larger particles. The relative time, for the particle to release all the volatile matter for both oscillating and non oscillating flows, increases as particle size increases. Secondary pyrolysis, thus, has a strong effect in devolatilization of large coal particles. Therefore, one may conclude that the effect of acoustic flow on pyrolysis is similar to a slight decrease in particle size at the same ambient gas condition.

The effects of oscillations on the entrainment of smaller particles are negligible. As particle size increases, up to 1.0 $\mathrm{mm}$, the difference in locations when devolatilization is under completion is more pronounced. Particle sizes of 0.5 and $1.0 \mathrm{~mm}$, in different flow conditions, have a great deal of volatiles released in the freeboard region implying that some dumping effect could cease the oscillations. Larger particles $(2.0 \mathrm{~mm})$, however, are heavy enough to stay almost stationary in the bed during the pyrolysis process.

The influence of the gas temperature on drying and devolatilization was also verified. The gas temperature was increased from 1300 to $1600 \mathrm{~K}$ and two simulations were carried out, with oscillating and non-oscillating flows for a $2.0 \mathrm{~mm}$ diameter particle. At the higher temperature particle heating is not so affected by the oscillations and, consequently, water evaporation rates as well as devolatilization rates are somehow similar for both flow situations. At $1300 \mathrm{~K}$ the heating rate of the particle in oscillating flow is much more pronounced. As a consequence, drying and devolatilization are much faster.

\section{Conclusion}

The following can summarize the parametric investigation presented in this work: a) the CPD model can be used to predict thermal degradation of coal particles in acoustic fields;

b) acoustic oscillations increase the evaporation and devolatilization rates of coal particles;

c) the CPD model predicted, in pulsating regime, the dynamic evolution of major light species and tar which are fundamental in the ignition and stabilization of flames;

d) the CPD model gave both quantitative and qualitative results for devolatilization under acoustic fields necessary for studying $\mathrm{NO}_{x}$ emissions;

e) small particles $(d<2.0 \mathrm{~mm})$ are carried over by the gas flow and would burn, mostly, in the freeboard;

f) conversely, larger particles would burn in the vibrating bed and would be entrained only after releasing a great deal of volatile matter since particle size is constant but density decreases;

g) lower tar yields and higher light gas production are observed as particle size is increased in oscillating flows;

h) oscillations do not increase particle heating and devolatilization rates at higher gas temperatures as it was observed at lower temperatures devolatilization.

\section{Acknowledgements}

C.A.G.V. and J.A.C.J. acknowledge the support of $\mathrm{CNPq}$ (Brazil) under project numbers 300854/97-8 and 301547/ 91-2, respectively.

\section{References}

1. Solomon, P. R.; Hamblen, D. G.; Carangelo, R. M.; Serio, M. A.; Deshpande, G. V.; Energy and Fuels 1988, 2, 405.

2. Solomon, P. R.; Serio, M. A.; Suuberg, E. M.; Progress in Energy Combustion Science 1992, 18, 133.

3. Genetti, D.; M.Sci. Dissertation, Brigham Young University, USA, 1999.

4. Belles, F. E.; Proc. of the Symposium on Pulse Combustion Technology for Heating Application, Argonne National Laboratory, Chicago, USA, 1979, p 167. 
5. Zinn, B. T.; Proc. of the Twenty-Fourth (International) Symposium on Combustion, Melbourne, Australia, 1992, p 1297.

6. Tyndall, J.; Physical Sciences, The Royal Institution Library of Science 1970, 2, 30.

7. Lord Rayleigh; The Theory of Sound, $2^{\text {nd }}$ ed., Dover: New York, 1945 re-issue, vol. 2, ch. 16.

8. Oran, E. S.; Gardner, J. H.; Progress in Energy Combustion. Science 1985, 11, 253.

9. Chu, B. T.; Stability of systems containing a heat source - the Rayleigh criterion, NACA-RM-56D27, NACA: D.C., 1956.

10. Ferreira, M. A.; Carvalho, J. A.; Journal of Sound and Vibration 1997, 203, 889.

11. Carvalho, J. A.; Ferreira, M. A.; Bressan, C.; Ferreira, J. L. G.; Combustion and Flame 1989, 76, 17.

12. Zinn, B. T.; Carvalho, J. A.; Miller, N.; Daniel, B. R.; Proc. Symposium on Pulse-Combustion Applications, GRI-82/ 0009.2, Atlanta, USA, 1982, p 11.1.

13. Carvalho, J. A.; Wang, M. R.; Miller, N.; Daniel, B. R.; Zinn, B. T.; Proc. Twentieth Symposium (International) on Combustion, Ann Arbor, USA, 1984, p 2011.

14. Carvalho, J. A.; Miller, N.; Daniel, B. R.; Zinn, B. T.; Fuel 1987, 66, 4.

15. Ferreira, M. A.; Carvalho, J. A.; Fuel 1990, 69, 684.

16. Torres, E. A.; Victório, J. R. S.; Ferreira, M. A.; Carvalho, J. A.; Fuel 1992, 71, 257.

17. Lacava, P. T.; Carvalho, J. A,; McQuay, M. Q.; Fuel 1997, 76, 845.

18. Dubey, R. K.; Black, D. L.; McQuay, M. Q.; Carvalho, J. A.; Combustion and Flame 1997, 110, 25.

19. McQuay, M. Q.; Dubey, R. K.; Carvalho, J. A.; Fuel 2000, 79, 1645.

20. Veras, C. A. G.; Saastamoinen, J.; Carvalho, J. A.; Proc. Fifteenth Brazilian Congress of Mechanical Engineering, Águas de Lindoia, Brazil, 1999.

21. Veras, C. A. G.; Saastamoinen, J.; Carvalho, J. A.; Brazilian Journal of Mechanical Sciences. 1999, 21, 200.

22. Veras, C. A. G.; Saastamoinen, J.; Carvalho, J. A.; Proc. of the Twenty Seventh Symposium (International) on Combustion, Boulder, USA, 1998, p 3019.
23. Veras, C. A. G.; Saastamoinen, J.; Carvalho, J. A.; Aho, M.; Combustion and Flame 1999, 116, 567.

24. Anthony, D. B.; Howard, J. B.; AIChE Journal. 1976, 22 , 625 .

25. Suuberg, E. M.; Peters, W. A.; Howard, J. B.; Proc. of the Seventeenth Symposium (International) on Combustion, Waterloo, Canada, 1978, p 117.

26. Unger, P. E.; Suuberg, E. M.; Proc. of the Eighteenth Symposium (International) on Combustion, Leeds, England, 1980, p 1203.

27. Niksa, S.; Energy and Fuels 1991, 5, 647.

28. Solomon, P. R.; Hamblen, D. G.; Carangelo, R. M.; Serio, M. A.; Deshpande, G. V.; Energy and Fuels 1988, 2, 405.

29. Niksa, S.; Combustion and Flame 1995, 100, 384.

30. Grant, D. M.; Pugmire, R. J.; Fletcher, T. H.; Kerstein, A. R.; Energy and Fuels 1989, 3, 175.

31. Solomon, P. R.; Hamblen, D. G.; Serio, M. A.; Yu, Z. Z.; Charpenay, S. C.; Fuel 1993, 72, 469.

32. Yavuzkurt, S.; Ha, M. Y.; Koopman, G. H.; Scaroni, A.; Proc. of the National Heat Transfer Conference, Houston, USA, 1989, p 133.

33. James, R. K.; Mill, A. F.; Letters in Heat and Mass Transfer 1976, 3, 1 .

34. Simons, G. A.; Combustion and Flame 1984, 55, 181.

35. Phuoc, T. X.; Durbetaki, P.; Intrenational Journal of Heat and Mass Transfer 1987, 30, 2331.

36. Fu, W.; Zhang, Y.; Han, H.; Duan, Y.; Combustion and Flame 1987, 70, 253.

37. Gosman, A. D.; Ioannides, E.; Journal of Energy 1983, 36, 482 .

Received: May 5, 2001

Published on the web: April 30, 2002

FAPESP helped in meeting the publication costs of this article. 